Southern Illinois University Carbondale

OpenSIUC

Publications

Department of Medical Education

6-2002

\title{
Learner Articulation as Interactional Achievement: Studying the Conversation of Gesture
}

Timothy Koschmann

Southern Illinois University Carbondale

Curtis LeBaron

Brigham Young University

Follow this and additional works at: http://opensiuc.lib.siu.edu/meded_pubs

Published in Cognition and Instruction, Vol. 20, No. 2 (June 2002) at 10.1207/S1532690XCI2002_4

\section{Recommended Citation}

Koschmann, Timothy and LeBaron, Curtis. "Learner Articulation as Interactional Achievement: Studying the Conversation of Gesture." (Jun 2002).

This Article is brought to you for free and open access by the Department of Medical Education at OpenSIUC. It has been accepted for inclusion in

Publications by an authorized administrator of OpenSIUC. For more information, please contact opensiuc@lib.siu.edu. 


\title{
Learner Articulation as Interactional Achievement: Studying the Conversation of Gesture
}

\author{
Timothy Koschmann \\ Department of Medical Education \\ Southern Illinois University \\ School of Medicine \\ P.O. Box 19230 \\ Springfield, IL 62704-9230 \\ e-mail: tkoschmann@acm.org \\ Curtis LeBaron \\ Department of Organization Leadership \& Strategy \\ Brigham Young University \\ Marriott School of Management. \\ TNRB 590 \\ Provo, UT 84602 \\ e-mail: lebaron@byu.edu
}

to appear in

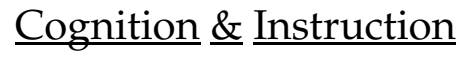




\begin{abstract}
Studied under a variety of names (e.g., self-explanation, self-directed and generative summarization), it is now a well-accepted finding that the process of learner articulation contributes to new learning. While prior research has focused on measuring the effects of various forms of articulation on learning outcomes, this report focuses on how such articulation maybe accomplished, moment to moment and turn by turn. Specifically, it documents some of the ways in which participants use their bodies and, in particular, their hands while displaying what they know. It presents fine-grained analyses of three videotaped fragments of naturally occurring interaction among medical teachers and students participating in tutorial meetings in a Problem-Based Learning curriculum. Within these three exhibits, we find evidence of recipient design with regard to gesture production and recipient response with reference to its performance. We also find evidence of gesture re-use as a mechanism for cohesion across turns at talk and as a display of mutual understanding. This paper represents a preliminary step toward a more general program of research focusing on sense making practices in learning settings. Extending our understanding of how such practices are accomplished interactionally is a crucial step toward eventually being able to give an adequate account of what makes any exemplary form of instruction effective.
\end{abstract}

Keywords: Classroom discourse, gesture studies, self-explanation, Conversation Analysis, sense making practices 
There exists thus a field of conduct ... which in its nature may be classed gesture. It consists of the beginnings of those actions which call out instinctive responses from other forms. And the beginnings of acts call out responses which lead to readjustments of acts which have been commenced, and these readjustments lead to still other beginnings of responses which again call out still other readjustments. Thus there is a conversation of gesture...

(Mead, 1910, p. 398)

\section{Learner Articulation}

There appears to be a growing consensus that giving voice to one's understandings contributes in important ways to learning. A variety of instructional activities, based upon this premise, have been proposed, including: learner-generated elaboration (Hamilton, 1989), self-directed (Brown, Day, \& Jones, 1983) and generative (Wittrock \& Alesandrini, 1990) summarization, constructive interaction (Miyake, 1986), collective comprehension activity (Hatano \& Inagaki, 1991), peer collaboration (Crook, 1994), selfexplanation (Bielaczyc, Pirolli, \& Brown, 1995; Chi, Bassok, Lewis, Reiman, \& Glaser, 1989; Chi, de Leeuw, Chiu, \& LaVancher, 1994; Coleman, 1998; Ploetzner, Dillenbourg, Preier, \& Traum, 1999; Renkle, 1997), classroom (Forman \& Larreamendy-Joerns, 1998) and elaborative explanations (Webb, 1989), construction of explanatory answers (Pressley et al., 1992), and reflective discourse (Van Zee \& Minstrell, 1997). All of these activities have been designed to create opportunities for learners to say what they know or, to use a more general term, to foster learner articulation.

Learner articulation has been described as having two different but potentially interrelated meanings: "the act of giving utterance ... to force a cohesive explanation" and "the action ... of jointing or interrelating ... of concepts and relationships" (Koschmann, Kelson, Feltovich, \& Barrows, 1996, p. 93). This first aspect of learner articulation, giving utterance, addresses the process of putting one's ideas into words. It is this sense of linguistic formulation, rather than the more technical sense of phonetic 
production, that is relevant when we speak of articulation in the context of learning. This aspect of learner articulation is presumably relevant to all of the instructional activities thought to contribute to improved understanding and listed in the previous paragraph. Jointing or interrelating of concepts, however, is also crucial to some, if not all, of these activities. ${ }^{1}$ The idea of jointing derives from the special sense in which anatomists use the term articulation, that is to fit elements together to form an integrated whole. In this metaphoric sense, articulation involves not only putting ideas into words, but also the bringing together and fitting together of words (hence ideas) in the process. Thus, the term learner articulation as we use it here accommodates the notion that learners may achieve new understandings, through the process of combining ideas, in the course of expressing them.

It is not at all obvious why articulation should necessarily benefit learning. If one assumes a simple transmission model of instruction, why should the playing back of information received lead to new learning? When learning is viewed as a purely mental occult process only amenable to indirect study, we are left at an impasse and have no means of resolving the puzzle of the learner articulation effect. Studying interaction in contexts of collaborative problem solving, however, allows us to gain some purchase on this problem. In effect it allows us to study learning directly as an interactional rather than a mental phenomenon. Our project becomes one of documenting how learners do articulation. We focus on one specific aspect of this problem, namely how learners use their hands and bodies in the process of displaying their understandings. We begin by examining earlier research on gesture and learning.

\section{Prior Research on Gesture and Learning}

Kendon (1987) defined gestures as "bodily movements that are clearly part and parcel of the individual's openly acknowledged intention to convey meaning" (p. 71)

\footnotetext{
${ }^{1}$ See, for example, the discussion of the constructive aspects of self-explanation in Chi et al. (1994).
} 
and, as such, is "treated as intentionally communicative by coparticipants" (p. 71, authors italics). He makes a further distinction among gestures that function as complete utterances in their own right, what he termed autonomous or emblematic gestures, and gesticulation "that seems to be bound up with [speech] as a part of the total utterance" (p. 75). In this paper, we will use the term gesture to refer to the spontaneous use of hands and, more generally, bodies that occurs as a normal part of face-to-face interaction and we investigate how learners employ gesture in articulating their knowledge.

Much prior research on the role of gesture in learner articulation has focused on what gesture reveals about learners' understanding. It is, therefore, in keeping with the first definition of learner articulation as giving utterance to a cohesive definition. For example, work conducted by Goldin-Meadow and her colleagues on children's explanations in various reasoning tasks (Church \& Goldin-Meadow, 1986; Church, Schonert-Reichl, Goodman, Kelly, \& Ayman-Nolley, 1995; Goldin-Meadow, Wein, \& Chang, 1992). In a report written by Goldin-Meadow, Alibali, and Church (1993), gesture is described as "a window into the mind of the child in transition" (p. 295).

Goldin-Meadow et al. (1993) defined transition as a "bridge between two rulegoverned knowledge states" (p. 279); that is, "an advance from an inadequate yet systematic understanding of a concept to a more adequate, systematic understanding" (p. 279). They theorized that the discordancy between talk and gesture reflects the fact that gesture provides "a vehicle ... better suited to capturing a child's understanding of a problem than is speech" (p. 292). Children in transition, by this theory, may be thought to be of "two minds" with respect to the problem at hand and their talk and associated gestures provide windows into both. In one series of studies (Church et al. 1986; 1995), children were asked to rationalize their judgments in a Piagetian conservation task. These researchers found that [1] these subjects often used gesture as a part of their explanation, [2] these gestures conveyed meaning, both to the 
experimenters and, in a later study, to naïve observers (Goldin-Meadow et al., 1992), and [3] the information embedded in these gestures was in some cases "discordant" or "mismatched" with the information conveyed verbally (Church et al., 1986). In more recent work, Roth (2000) has examined gesture-speech mismatch in science-related explanations produced by high school students.

Other studies treat gesture not only as an external manifestation of understanding, but also reflecting a constructive process of connection-making. Such a view is more consistent with the second definition of learner articulation as a jointing or interrelating of concepts. Crowder (1996), for example, described explanatory sense making as "the process of explaining observed phenomena through coordination of theory and evidence" (p. 174). She investigated students' use of gesture in an elementary classroom, choosing as a unit of analysis, student performances, that is "a child's response to a given question or speaking task posed by a teacher or another child" (Crowder \& Newman, 1993, p. 354). Crowder (1996) made an analytic distinction between two forms of classroom science talk: descriptive talk about science and a form of explanation she describes as "running models" (p. 177). While the former represents a more stable mode of recitation, the latter involves "explaining in-the-moment" (p. 201) or, as she also referred to it, "explaining to self" (p. 205). In that it consists of "talk that has not been thought out prior to its expression" (Ochs, 1979, p. 55), such forms of explanation entail extensive "planning-in-the-moment" (Crowder, 1996, p. 204). As a result, they are often unpolished and marked by breaks, restarts, and self-correction. In such situations, however, learners appear to achieve "conceptual glimmerings that outstrip scientific vocabulary" (Crowder \& Newman, 1993, p. 371).

The Crowder studies were important in directing our attention to the constitutive nature of gesture use in learner articulation. By limiting her frame of analysis to the performances of individual gesturers, however, her studies present a potentially restricted view of how gesture is employed in learner articulation. In this report, we 
examine how gesture serves as one of several interactional resources available to participants engaged in joint sense making. In so doing, we offer empiricallygrounded evidence for what might be termed, borrowing a phrase from Mead, the "conversation of gesture." As you will see, gestures are more than auxiliary communicative devices; they are actions that shape and help reflexively constitute a social order, which cannot be separated from the understandings that interactionally emerge through teaching/learning processes (LeBaron \& Streeck, 2000). We argue that studying the conversation of gesture can contribute in important ways to our understanding of how participants do learner articulation.

\section{Data and Observations}

Learner articulation depends upon communicative behaviors that can be heard and seen by participants and researchers alike. Through close and detailed analysis of video recordings, it is possible to identify specific features of learner articulation-vocal and visual behaviors that are individually coordinated and socially organized to make sense. The methods employed here, then, derive from the family of analytic traditions devoted to the study of naturally occurring speech and movement (see Duranti, 1997). These traditions include: "interaction analysis" (Jordan \& Henderson, 1995), "video analysis" (e.g., Heath, 1986) Conversation Analysis (Atkinson \& Heritage, 1984; Drew \& Heritage, 1992; Goodwin, 1981), and context analysis (Scheflen, 1973; Kendon, 1990).

In earlier work (e.g., Koschmann, Glenn, \& Conlee, 2000) we examined how participants in a learner-directed method of instruction known as Problem Based Learning (PBL) made their understandings visible to themselves and their peers. In a PBL curriculum, students collaboratively explore a series of authentically-constructed problems identifying deficiencies in their collective understanding ("learning issues") and independently research these matters in a self-directed manner (Barrows, 1994). Articulation has been identified as a critical component of participation in a PBL 
curriculum. It has been argued, for example, that "participation in the PBL process dictates that students continuously put their ideas before the group" (Koschmann et al., 1996, p. 102). For this reason, PBL meetings would appear to be an ideal setting for studying the ways in which learners use gesture while articulating newly acquired knowledge.

We present and analyze three videotaped fragments, taken from a data corpus of over 140 hours of PBL meetings recorded at a midwestern U.S. medical school. We use the transcription conventions developed by Gail Jefferson (see Atkinson \& Heritage, 1984), which are summarized in Appendix A. Full transcripts for the three analyzed fragments can be found in Appendices B, C, and D. ${ }^{2}$ Participants' names have been altered.

\footnotetext{
${ }^{2}$ Digitized video for the three fragments can be downloaded from the following site: http://edaff.isumed.edu/tk/articles/gestures/.
} 


\section{Exhibit 1: "Where is the hippocampus?"}

Description of data. Our first videotaped fragment has been extracted from a longer segment ${ }^{3}$ involving second-year medical students and a faculty facilitator (Coach). The participants sat around a table, oriented toward each other and various medical texts (see Fig. 1). After a query from Coach (line 1, see Appendix B), participants collaboratively formulated the location of a brain structure known as the hippocampus. Norman self-selected (line 4) to respond to Coach's query and employed an anatomical flipchart on the opposite end of the room as a visual resource (see Fig. 1). Maria made multiple efforts to amend Norman's formulation, the third of which (lines 15 and 16) was coordinated with an analytically interesting gesture, which is the focus of our analysis.

\section{Maria: S'like- if: you lift up that little temporal lobe, 16 it's on the inside.}

Maria's use of "s'like" framed her comment (and its associated gesture) as metaphor. Concurrent with the utterance of this first syllable, Maria raised her right hand from below the table. As she said lift, she executed a pinching motion using her thumb and index finger (Figs. 2a and 2b). She then forcefully lifted her arm above her head with her elbow held high, at the same time pitching her head slightly backwards. At the completion of this motion and coincident with the word that, she twisted her hand counterclockwise exposing the inside of the hand (Fig. 2c). She then returned the hand below the table, but almost immediately raised it again to perform a second gesture

\footnotetext{
${ }^{3}$ The fragment described here is part of a longer six-min. segment that was described by multiple analysts in a special issue of Discourse Processes (Koschmann, 1999). Previously published descriptions of gesture use within this fragment can be found in Lemke (1999) and Hall (1999).
} 
synchronized with the word on. The gesture was performed with a closed hand that was twisted on the second syllable of in-side. Though the gesture was made clearly visible to her audience, Maria was turned away from the camera at this moment and, as a consequence, our view of this second gesture is partially blocked. Our comments pertain to Maria's first gesture.

Maria's utterance and associated gesture call upon her listeners to make a shift between the 2-D representations of the flipchart (which Norman has referenced) and the 3-D representation of the metaphorical brain suggested by her first gesture. Her gesture, in effect, acts out a projected dissection of her own cerebral cortex. ${ }^{4}$ What is remarkable about this shift in orientation is how unremarkably it was treated by her cointeractants. No one appeared confused or startled by this change in orientation. Instead, Coach (line 17) was able to seamlessly map Maria's description back onto the flipchart atlas by redirecting the attention of the group toward an alternate section where Norman (with the help of another student, Lill) was then able to successfully locate-on the flipchart-the region specified by Maria. Her gesture provides us with an elegant example of the situated nature of gesture production.

Observations. A striking feature of Maria's gesture is the degree to which it can be seen to be recipient-designed. Sacks, Schegloff, and Jefferson (1974) described recipient design as the "multitude of respects in which the talk by a party in a conversation is constructed or designed in ways which display an orientation and sensitivity to the particular other(s) who are co-participants" (p. 727). They analyzed the ways in which speakers used recipient design in "word selection, topic selection, admissibility and ordering of sequences, options and obligations for starting and terminating conversations, etc." (p. 727). Schegloff (1972) observed, "if one looks to the places in conversation where an object (including persons) or activity is identified (or as I shall

\footnotetext{
${ }^{4}$ This metaphoric description was suggested by Hall (1999).
} 
call it, 'formulated'), then one can notice that there is a set of alternative formulations for each such object or activity, all the formulations being, in some sense, correct (e.g., each allowing under some circumstances 'retrieval' of the same referent)" (p. 80). He described two bases for selecting a particular formulation: membership and location analysis. Membership analysis requires consideration of "the categories ... of the society of which the hearer(s), in the first instance, but also the speaker are members" (p. 88). Location analysis, on the other hand, arises from "an analysis of [the speaker's] location and the location of his co-conversationalist(s), and of the objects whose location is being formulated" (p. 83). Schegloff et al. (1974) described recipient design in lexical construction. As we will show here, however, recipient design also enters into gestural performance.

Maria's lifting gesture assumed a shared understanding of what a temporal lobe is, where it is located (i.e., in the brain), and the fact that it can be lifted away from the rest of the brain. Her gesture would hold little meaning for an audience unfamiliar with these aspects of human neuroanatomy. We might refer to it, therefore, as an "insider gesture," ${ }^{5}$ because it presumes certain forms of special knowledge shared by the speaker and audience. The use of insider gestures is related to recipient design in that the gesture provides evidence of the sort of membership analysis described by Schegloff.

We also see evidence that Maria, in her gestural performance, was attending to certain aspects of the local situation, that is she was engaging in what Schegloff termed "location analysis." In the first place, her three-dimensional performance was made recognizable against the temporal and spatial backdrop of Norman's two-dimensional charting. Her gesture depends upon his earlier pointing and the still visible

\footnotetext{
${ }^{5}$ An insider gesture should not be confused with an "insider perspective" as described by McNeill, 1992) and Crowder (1996).
} 
representation on the flipchart to resolve the indexical reference to "that little temporal lobe" and to make clear with relation to what "on the inside" was referring. In the second place, her gesture used her own present (but not visible) brain as an object to orient her audience to the three-dimensional location she was attempting to specify by, in effect, gesturally lifting her own temporal lobe. The sense of her gesture depended not only on the action of her hand, however, but also on the presence of her own body as a relevant backdrop for this performance.

Hutchins and Palen (1997) provided a rich account of how gestures participate in what they referred to as a "multilayered representation" (p. 35). Gestures both draw upon and elaborate the complex of semiotic resources employed in practical sense making. Hutchins and Palen described how deictic gestures (i.e. points) acquire their determinate sense by virtue of being superimposed upon relevant aspects of the material environment. Similar observations have been made by Goodwin (in prep), Hindmarsh and Heath (2000), LeBaron and Streeck (2000), and Streeck (1996).

Maria's lifting gesture differs, however, from these earlier accounts of situated gesture use in that the material environment against which her gesture is juxtaposed are aspects of her own body. The action, therefore, is performed by the hand, but its meaning resides in a larger context that embraces salient features of the material environment, especially the speaker's corporal form. Some researchers have examined the diectic gestures of patients who bring attention to their bodies during medical examinations (e.g., Heath, 1986, 1988; Beach \& LeBaron, in prep). By contrast, Maria's gestures are iconic (see McNeill, 1992, for a description of gesture types) representations of her hidden (albeit proximate) gray matter.

Because the performance of a gesture is recipient designed, its meaning is inherently situation-bound. Our ability as analysts to make sense of the exchange and, in particular, what is being accomplished by Maria's gesture depends crucially upon our access to the material and social context within which it was produced. This exhibit 
illustrates how speakers' talk and gestures furnish clues that "engage their recipient's common sense knowledge of the world, their recipient-designed mutual knowledge, and their orientation to the occasion of the conversation" (Schegloff, 1988, p. 444). Said another way, it reveals certain ways in which knowledge takes an embodied form.

\section{Exhibit 2: "Serial x-ray"}

Description of data. As was the case with the first exhibit, our second videotaped fragment has been extracted from a longer segment of interaction. ${ }^{6}$ It was recorded in a different PBL meeting with a different group of participants. Like the previous exhibit, the students and tutor sat at a table containing notes, textbooks, and materials relevant to the case under discussion (see Fig. 3). As the fragment began, participants were discussing the possible risks of performing an abdominal CT (Computerized Tomography) scan on a young female patient. Many gestures were performed over the course of this discussion as the topic repeatedly shifted-from potential risks, to differences between conventional X-rays and CT scans, to an attempt to estimate the differences in radiation exposure between a conventional X-ray and a CT scan. Our analysis focuses on an exchange between Joel and Jackie (lines 12 to 21).

First, Joel offered a refinement of the Coach's question, showing an understanding at least sufficient to pursue the line of inquiry:

\section{Joel: What is the dosage (0.4) relative (.) from uh normal $13 \mathrm{X}$ - ray to a $\mathrm{CT}_{\dot{c}}$}

While raising the difference between an X-ray and CT scan, Joel partitioned the use of his hands. During his 0.4 second pause, Joel lifted his right hand (see Fig. 4a). Immediately prior to the word "X-ray," he lifted his left hand into his gesture space and

\footnotetext{
${ }^{6}$ A description of the extended segment was provided by Koschmann et al. (2000).
} 
thereby associated it with "X-ray" (see Fig. 4b). Then he said "CT" and at the same time jerked his right hand (already lifted) and thereby linked it with "CT" (see Fig. 4c).

Altogether, Joel associated his opposing hands with the concepts being contrasted. His hands were used metaphorically, held in front of him like containers to hold ideas, in a manner reminiscent of McNeill's (1992) discussion of the conduit metaphor in gesture.

After posing a question (lines 12 and 13), Joel self-selected to answer it. His next utterance involved a complex sequence of gestures, including a "slicing" gesture that was coordinated with a knowledge claim about CT scans being "serial":

14 Joel: $\quad\lceil\mathrm{CT}$ is $\uparrow$ serial $\mathrm{CT}\rceil{ }^{\circ}$ is it $^{\circ}$ serial $\mathrm{X}$-rays $>$ is it not<?

At the same time that Joel said "serial CT," he gestured with his right hand, which was already associated with the notion of CT scan. He rotated his right hand $90^{\circ}$ clockwise into a vertical position with his thumb pointing upward (Fig. 5c). He then executed a chopping motion in a plane parallel to his body (Fig. 5d). His third and final movement began with Joel raising his right hand within the plane constructed in the previous movement (Fig. 5e), but this time as the hand was dropped it was drawn toward his body (Fig. 5f). Eventually, his right hand was retired to his lap.

Converting his statement into an interrogative form by adding "Is it not?," Joel softened his assertion and at the same time made a next speaker relevant. By directing his gaze toward Jackie, Joel nominated her as the next speaker or respondent to his display of knowledge. Coach and Patrick both ratified this nomination by turning their attention in Jackie's direction, and Patrick pointed toward her using the pinky of his right hand. On cue, Jackie responded through vocal and gestural behaviors that recognizably built upon Joel's contribution.

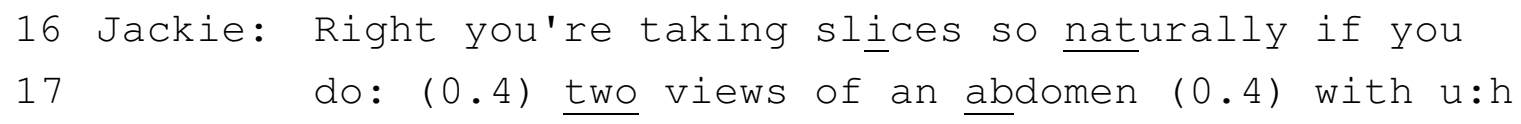




$$
\begin{aligned}
& \text { plane film (0.2) and you do: (0.5) fifteen with (.) } \\
& \text { uh }
\end{aligned}
$$

Ctee (.) ${ }^{\circ}$ I mean' but I don (.) I don't know (.)

From the outset, Jackie positioned herself as aligned with Joel regarding the issue at hand. The statement "Right you're taking slices," however, was an endorsement not merely of what Joel said but of what Joel gestured. As she enunciated "taking slices" Jackie reproduced Joel's CT gesture making three slicing down strokes-and she used her right hand, consistent with Joel's earlier partitioning. Joel answers (albeit silently) with an abbreviated version of this same gesture. ${ }^{7}$

As Joel did with his compare/contrast gesture, Jackie gesturally set up a contrast between two ideas. As she began the phrase "the relative dosage," she raised both hands off the table. With the enunciation of relative, she pushed both hands down as though playing on a keyboard (Fig. 6a) and then lowered them to the table. But when she started the phrase "one slide of CT," she raised and then dropped her right hand only (Fig. 6b). As she began the contrast ("versus (one)"), she repeated this movement with her left hand (Fig. 6c). In so doing, she reproduced Joel's association of the right hand with the concept of CT scans and the left hand with conventional X-rays. Jackie's compare/contrast gesture differed from Joel's, however, in that hers was preformed with the hands palm down as though the two concepts were objects on the table rather than things balanced in the hands. The conversation continued, but this exposition will suffice for our current purposes.

\footnotetext{
${ }^{7}$ It is widely held (cf., McNeill, 1992; Schegloff, 1984) that gestures are principally produced by speakers and only rarely by listeners. However, many examples of a recipient-produced gestures, such as Joel's gesture here, can be found in this data corpus.
} 
Observations. In this exchange we observe certain interactional features relevant to two issues discussed in the literature devoted to the study of gesture, namely recipient response and gestural cohesion. Both are important to the development of our understanding of gesture as a conversational phenomenon.

In practical situations, it is often difficult to tease apart the contribution of gesture, talk, and the other semiotic resources employed in the construction of meaning. Indeed, some researchers (Krauss, Morrel-Samuels, \& Colasante, 1991; Rimé, 1983) have gone so far as to argue that gesture has no unique communicative role. Goodwin (1986) proposed that claims to the effect that "gesture is in some way consequential for recipients" (p. 30) must be grounded upon clear evidence of what he termed "recipient response" (p. 30), that is "by responses to the gestures as events in themselves" (p. 30). Studying the ways in which hearers respond to a gesture is a special instance of a more general research strategy widely used in CA research and known as sequential analysis (c.f., Goodwin, 1981; Sacks, 1992). Sequential analysis seeks grounds for interpreting social action by examining the ways in which the action is subsequently treated by participants. Goodwin's call for an analysis of recipient response, therefore, is a call for a sequential analysis of gestural displays.

When we examine the unfolding interaction here, we see clear evidence of recipient response. Jackie's "Right you're taking slices" (line 16) put into words something that Joel had only communicated through gesture. His CT gesture not only supported what he contributed lexically, it extended it semantically. Joel's gestural response to Jackie's reproduction of his own prior slicing gesture is an example of what de Fornel (1992) referred to as a "return gesture" (p. 163). It is a visible action on the part of a recipient to a gesture to both acknowledge and display attentiveness to it. Both Joel's return gesture and Jackie's allusion to Joel's previous gesture constitute evidence for recipient response under the criterion proposed by Goodwin (1986). 
A second issue, highly relevant to the role of gesture in learner articulation has to do with gestural cohesion. Halliday and Hasan (1976) used the term cohesion to describe the various mechanisms by which linkages are constructed across units of discourse. Among these, they included the lexical cohesion that is achieved through simple repetition of a textual element across separated units of text. McNeill and Levy (1993) provided examples of how gesture can also be employed to produce a form of gestural cohesion. They described how the hand with which a gesture is performed, the space within which a gesture is produced, or the form of the gesture itself can contribute to topical cohesion across turns at talk.

The examples provided by McNeill and Levy applied only to gestural cohesion across units of talk produced by a single speaker. Other researchers have described how gestures are repeated across different speaker's turns as talk. Von Raffler-Engel (1986), for example, described how certain gestures could, on occasion, be transferred from speaker to listener. LeBaron (1998) studied professional architects interacting with clients during several meetings over a six-month period and found that certain hand gestures initially performed by the architects were subsequently appropriated by the clients. We see here in the exchange between Joel and Jackie how reproduction of a previously performed gesture can serve to link together elements of a conversation. Jackie's reuse of Joel's slicing gesture can be seen to connect her discussion of CT scans back to his. Further, by applying Joel's convention of associating the right hand with CT scans and the left hand with conventional X-rays, she created a link back to Joel's prior discussion. As another example of gestural cohesion, consider earlier when Joel self-selected to answer his own question (line 14). He chained together his just completed compare/contrast gesture with what became in his second utterance an iconic gesture for a CT scan. By performing the latter gesture with his right hand, he exploited the distinction constructed in his prior utterance. In all three examples, the 
repetition of a gesture or one feature of a gesture served to tie together sequential pieces of the unfolding conversation.

Previously, we cited evidence for recipient design in gesture performance as one justification for the need to study gesture conversationally. Recipient response and gestural cohesion similarly argue for adopting a frame of analysis that goes beyond an examination of the gesture (and gesturer) in isolation. The meaning of a gesture resides not in the gesture itself, but in its relationship to preceding (and succeeding) forms of visible and vocal interaction. All three issues (recipient design, recipient response, and gestural cohesion), therefore, serve to highlight the importance of including the social and material environment, as well as the conversational history in the analysis of gestural performance. To this point, however, we have only examined these issues with regard to extracted exchanges. In the next exhibit, we will explore the use of gesture in a more elaborate segment of interaction.

\section{Exhibit 3: "Can you define thrills?"}

Description of data. Our final fragment involves two groups of participants communicating via a video-conferencing system-one a group of graduate nursing students, the other a group of first-year medical students. ${ }^{8}$ Although the groups were physically separated by 180 miles, they were virtually brought together as one televised image that all participants could see and hear. In the recording, the PBL facilitator (again identified as "Coach") and three medical students appeared in the picture-inpicture (PIP) window on the lower right of the screen (see Fig. 7). At both locations,

\footnotetext{
${ }^{8}$ The fragment analyzed here represents an example of a complete "knowledge display segment" as described by Koschmann et al. (2000). This particular segment was described previously by LeBaron and Koschmann (in press).
} 
participants sat in a semi-circle around a large table so that they could easily orient toward each other, toward a common paper-based case simulation (one copy at each site), and toward the video-conferencing equipment (camera and monitor) that enabled communication with the remote group. Because all participants had to orient toward their local cameras in order to see and be seen by the participants at the remote site, this teleconferenced meeting provided an excellent setting for studying the ways in which people use their hands and bodies while articulating their knowledge.

The eight participants explored a particular clinical case by reading and discussing a specially-formatted, text-based simulation (Distlehorst \& Barrows, 1982). The case involved an elderly female patient being examined after an incident in which she briefly lost consciousness. The participants encountered the technical term thrills while reading the results of a cardiovascular exam, setting the stage for an interval of knowledge display. Jack, one of the medical students, turned the term thrills into a question that Bill, one of the nursing students, self-selected to answer:

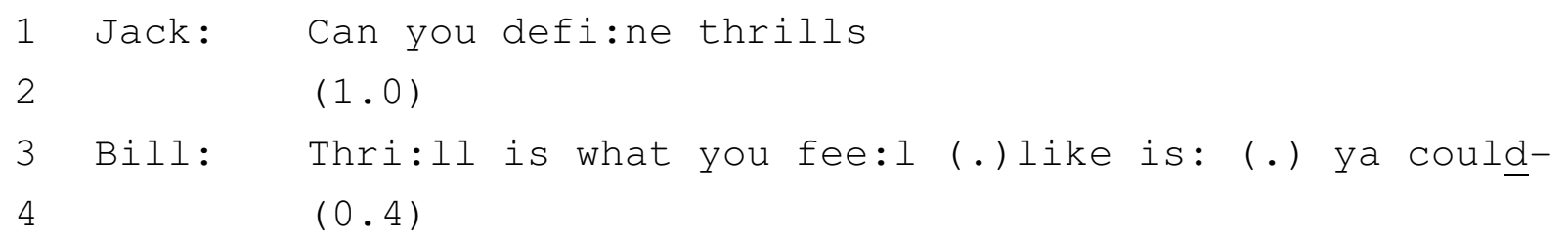

After a brief pause, Bill self-selected to respond to Bill's query. Prior to speaking, he lifted his left hand to his chin. As he looked up to speak, he brought this hand forward and wiggled his fingers repeatedly (Fig. 8a). By coordinating this gesture with the lexical affiliate feel, Bill's gesture was made recognizable as a sort of tactile representation - that is, his moving fingers were performing the behavior and hence the experience of feeling with the hand.

Unfortunately, however, Bill failed to complete a coherent response. That is, he did not produce an utterance that was hearably complete, and he repeatedly paused during his turn at talk while restarting his utterance several times, in each case 
changing the trajectory of his explanation. His first restart was marked by the words "like is" and a second occurred with the words "ya could." Each restart was coordinated with a shift in the shape of his gesturing hand. When Bill said "like is," his fingers stopped wiggling as they came together in a closed and rounded shape (Fig. 8b). As he said "ya could," he formed another gesture as if reaching for something situated on his shoulder (Fig. 8c). As his uncompleted utterance trailed off, however, this gesture devolved into a neck scratch. Thus, Bill's display of understanding came up short. His eye gaze also shifted away from the monitor and off to one side as though withdrawing from the interaction.

Susan (who sat to the immediate right of Bill) picked up where Bill left off. During Bill's utterance, Susan was oriented toward the monitor and, therefore, witnessed the onset and the eventual suspension of Bill's knowledge display. Susan then self-selected to follow him as speaker and stated:

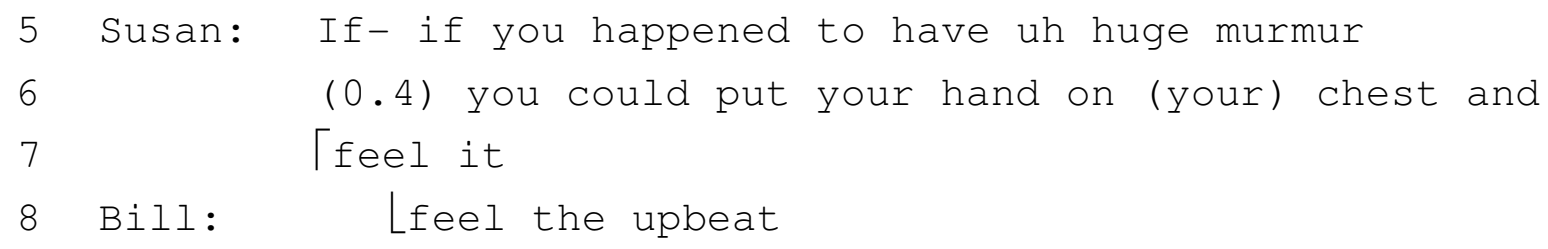

Unlike Bill's, Susan's formulation was hearably complete. The syntactic and prosodic structure of her utterance constituted a transition relevance place (Sacks, Schegloff, and Jefferson, 1974) after the words "feel it." Moreover, her utterance was coordinated with a recognizably coherent gesture. At the beginning of her utterance (with the words "ifif"), Susan lifted her right hand to her chest, locating it where a heart beat might be felt; with the words "you could" she lifted her flattened hand a few inches from her chest and then returned it (Fig. 9a). In sum, Susan performed a hand-felt heartbeat, albeit exaggerated in form.

Notice Bill's alignment with Susan's knowledge display. Bill collaboratively completed Susan's utterance with the words "feel the upbeat." His collaborative 
completion evidenced that he heard and understood her description sufficiently to complete it in overlap with her. After scratching his neck, Bill looked toward the monitor where Susan's hand was visibly flattened against her chest, at which point Bill lowered his hand toward his own chest and spreads his fingers in a flattened form. In another example of what de Fornel (1992) referred to as a "return gesture," Bill reproduced Susan's gesture in concert with her (Fig. 9b). Through such vocal and visible displays of alignment, Bill showed that Susan's performance was an appropriate continuation of the knowledge display that he had started.

Continuing their response to Jack's question about "thrills," the nursing students coordinated their vocal and visible behaviors in the course of displaying their understanding. After collaboratively completing Susan's description, Bill self-selected again and explained further:

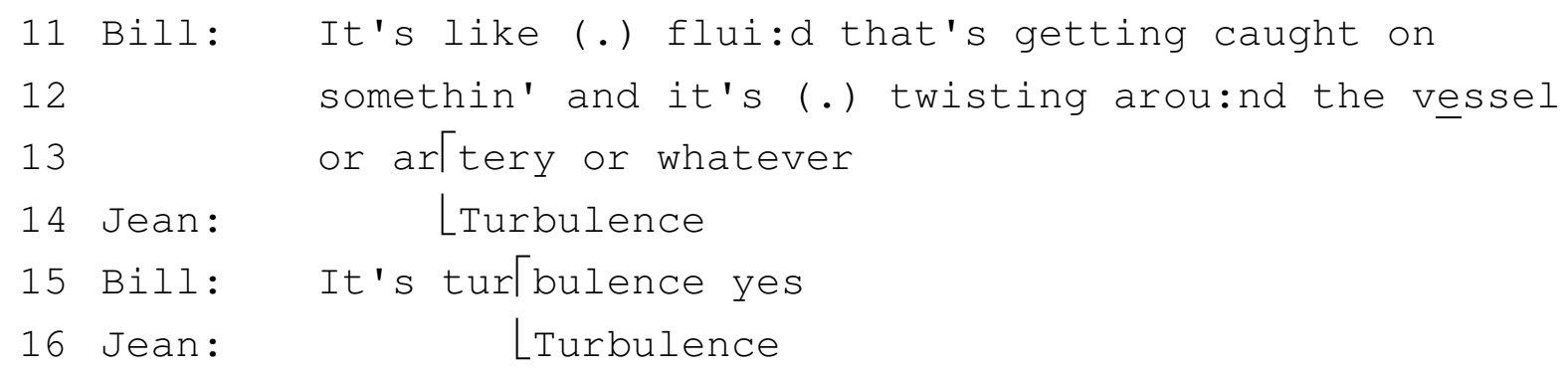

Notice the form and content of Bill's explanation: an utterance-initial hedge (i.e., "it's like"), followed by hesitations (pauses) and nondescript words (e.g., "somethin" and "whatever"), came together in an extended narrative about blood within the heart getting "caught" and "twisting around"-action words not usually associated with fluids. Bill's utterance would appear to be an example of Crowder's (1996) "explaining in-the-moment" (p. 201), that is, unpolished expressions marked by breaks, restarts, colloquialisms, and self-corrections. Nevertheless, Bill's vocal explanation was coordinated with a hand gesture that was recognizable and evidently consequential. 
With his index finger extended, Bill rotated his left hand in the air to iconically represent the movement of fluid swirling within a chamber (Fig. 10). This motion was sustained throughout the utterance produced in lines 11 to 13 . Jean (sitting to Bill's immediately left) observed Bill's gesture (see Fig. 10) before speaking the word "turbulence." By speaking in overlap, Jean intervened, behaving as though Bill's vocal expression required immediate vocal assistance. By speaking only after Bill's gestural performance but before the end of his utterance, Jean behaved as though Bill's gesture was instrumental in occasioning her contribution. Goodwin and Goodwin (1986) described some of the ways in which pauses, gestures, and gaze are employed by speakers as a means of inviting listeners to collaborate in the search for a word. It is not clear in this instance, however, that Bill was actually engaged in the search for the term turbulence. Nonetheless, Jean provided it (line 14) and Bill repeated it (line 15), literally incorporating it into his description of "thrills." Through his repetition of Jean's word, Bill treated Jean's interjection as collaborative and he immediately aligned himself with her contribution to his interactive display of knowledge.

Bill then clarified the difference between a thrill and a murmur (bruit). He began:

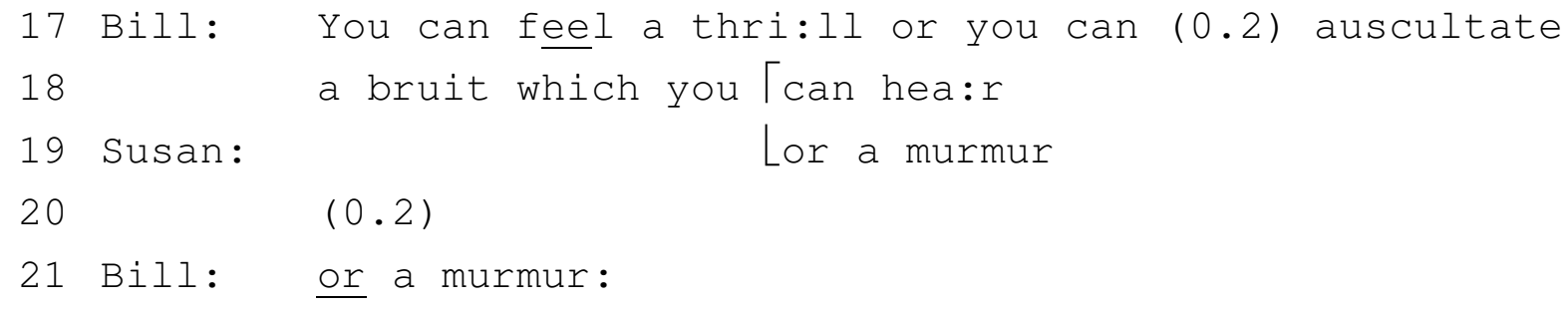

Bill reinforced this distinction by employing different gestures to illustrate the actions. At the onset of feel he fleetingly reproduced Susan's flat-handed gesture for feeling a thrill, but, instead of feeling his own heart he pushed his flattened hand away as if touching an imaginary patient (Fig. 11b). His gesture, therefore, connected to but also extended Susan's. Coordinated with the word hear he performed a series of 
movements that resembled the placing of a stethoscope on the chest of an imaginary patient (Figs. 11c and 11d), a procedure that physicians refer to as auscultation. ${ }^{9}$ Like Maria's gesture in Exhibit 1, Bill's second gesture was an insider gesture; it presumed a certain form of background knowledge on the part of the recipient(s).

The last two words of Bill's utterance were overlapped by another speaker. This time it was Susan who interjected or moved to clarify the unfolding knowledge display. Speaking in overlap with Bill, Susan offered a less technical term for bruit (line 19). As before, Bill repeated the contribution (line 21) verbatim, thereby registering Susan's collaboration in the articulated response.

When the nursing students stopped speaking and turned away from the monitor, showing that their response to Jack's question was complete, Marie (a medical student at the other site) reiterated the emergent understanding. Turning to the other medical students, she said:

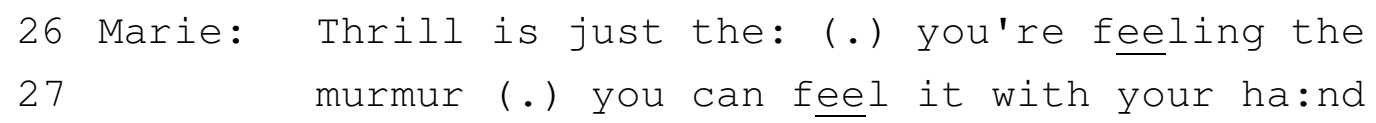

\footnotetext{
${ }^{9}$ Prior work on gesture and talk has focused on the sequential positioning of gestures relative to semantically-related lexical elements, sometimes referred to as "lexical affiliates" (Schegloff, 1984, p. 276). Schegloff wrote, "the critical property of iconic gestures ... is that they are pre-positioned relative to their lexical affiliates" (p. 276). Crowder (1996) also discussed the issue of "gestural foreshadowing" (p. 190) and Roth (2000) reported findings that suggested that the latency between gestural performance and subsequent utterance of the affiliated lexical element declines with increasing expertise. The identification of the affiliated lexical element can in some cases be problematic, however. Looking at Bill's turn at talk, for example, how do we choose which lexical element is affiliated with his gesture? If one selects hear, then the gesture is not pre-positioned, but concurrent with its lexical affiliate. On the other hand, if one chooses ausculatate, then the gesture follows its lexical affiliate.
} 
Marie's recap selectively employed vocal and visible behaviors performed by the nursing students. Her words murmur, feel, and hand were previously spoken by the nursing students. Moreover, Marie coordinated her utterance with hand gestures that unmistakably resembled Susan's (and Bill's) prior performance. With the word thrill, Marie placed her flattened hand onto her chest; with the word feeling, she lifted her hand from her chest and then returned it. Her formulation, therefore, appropriated the vocal and visible behaviors that the nursing students provided earlier.

Observations. Jack's question "Can you define thrills?" occasioned an interval of knowledge display involving several nursing students who coordinated their vocal and visible behaviors to achieve a joint articulation, which was subsequently reformulated by one of the medical students at the distant location. Multiple participants contributed a necessary part-a key word, a gesture, a phrase-whereby an acceptable whole was eventually composed and knowledge interactively displayed. In the gestures employed, we find evidence of recipient design, recipient response, and gesture used as a means of accomplishing cohesion across turns at talk.

Moerman (1990), in an article entitled "Studying Gesture in Social Context," made a series of observations about gesture (i.e., "Gestures occur in conversations" [p. 16], "Gestures communicate" [p. 16], "Interactive events are typically multi-modal" [p. 16], "Interactive events are typically multi-party" [p. 16], "Gestures are affiliated to utterances" [p. 17], "Gestures are interactive phenomena in as much as they serve to regulate co-presence, affect the actions of others, accomplish something in the social world, and so contribute to and partially constitute social actions" [p. 17]). Though his points might attract controversy in some circles, our observations in the last exhibit fully support his view of gesture as a form of interactional achievement. Susan's gesture, subsequently taken up by Bill and Marie, becomes a local semiotic resource for talking about murmurs and thrills. Her gesture (and associated talk) sets up a potential misunderstanding, however, that Bill later attempts to rectify. He does so by 
contrasting a variant of Susan's gesture with a new gesture presumably recognizable to the participants as an enactment of listening (auscultating) with a stethoscope. These gestures served both to contribute to and constitute the socially-organized activity of articulating their knowledge.

From his list of observations Moerman (1990) developed a set of precepts for the study of gesture as an interactive phenomenon (e.g., gestures should not be studied in isolation from other visible activities, gestures should be viewed as parts of sequences and social moves and, as a result, there should be an analytic focus on "participant's orientation to interactional boundaries" [p. 39], that we should give full heed to gesture's consequences for "the organization of co-presence and for the performance of social actions" [p. 39]). It is only by carefully following these precepts, Moerman argued, that researchers can give an adequate account of why any particular gesture occurs when it does. We consider his arguments to be entirely consistent with the case made in the current paper for the need to undertake a careful study of the conversation of gesture.

Our call for a study of the conversation of gesture, however, should not be construed as a suggestion that gestures can be studied as a form of conversation independent of talk. In borrowing this expression from Mead we employ it to encompass not only the conversation among gestures, but also the ways in which gestures themselves engage in conversation with other forms of visible and vocal communicative behavior. We demonstrate in these exhibits, how gesture is shaped by the social context within which it is produced. We saw, for instance, how gestural performance is sensitive both to the composition of the audience (recipient design) and to prior interaction (gestural cohesion). At the same time, we saw evidence of the consequentiality of gesture for the development of subsequent understanding (recipient response). We are, therefore, quite in accord with Moerman's arguments to the effect 
that gestures are not interpretable as actions in and of themselves, but are instead better understood as facets of larger and more extensive forms of social action.

\section{Concluding Thoughts}

The current study represents a preliminary effort toward improving our understanding of learner articulation as an interactional achievement. Specifically, we provide grounded evidence of certain features of gestural performance (i.e., recipient design, recipient response, gestural cohesion) within the context of learner articulation. Learner articulation was described in prior writing (Koschmann et al., 1996) as having two different but potentially inter-related meanings: one of giving utterance and the second an action of constructing connections or jointing. Our findings with regard to the role of gesture in learner articulation lead us to understand both definitions in new ways.

From a cognitivist perspective, the act of giving utterance is simply an instrumentality for making visible an internal state of affairs. Giving utterance, however, is also an interactive event and, as Moerman (1990) pointed out, interactive events are typically multi-modal. This was amply demonstrated in the three exhibits in which we found numerous examples of interactants actively employing their hands and bodies and aspects of the material environment while displaying their understandings. The ways in which gestures are designed for use with particular audiences and within particular conversational contexts offer important evidence for the situated nature of learner articulation. For example, Maria's gestural performance of lifting of her temporal lobe in Exhibit 1 and Bill's demonstration of auscultation in Exhibit 3 both show how gesture is shaped and informed by its social and material context. Since these situated aspects of gesture use are only made visible in conversational contexts, 
they argue persuasively for the need to study gesture and, by extension, learner articulation interactionally.

The action of making connections or jointing could also be construed in purely cognitive terms, focusing exclusively on the learner's construction of conceptual linkages. When we adopt a wider frame of reference, however, and examine the establishment of connections across contributions offered by different participants to a conversation, we see the action of jointing in a different light. In the three presented exhibits we saw evidence of the ways in which gesture contributes to this process. First, we saw that interactants respond directly to gestures as semantically-laden elements of unfolding discourse (see Jackie's response to Joel's gesture in Exhibit 2, for example). Gesture is clearly more than redundant "communicative behavior" as has been suggested by some authors (e.g., Krauss et al., 1991; Rimé, 1983). But it does more than simply contribute to conceptual development; gesture is one of the means by which interactional jointing is actually achieved. We saw in Exhibits 2 and 3, for instance, how the repetition of gestural forms is an important mechanism for establishing semantic links across turns at talk. Gesture is conversationally consequential, therefore, and contributes in important ways to interactional jointing.

Our paper focuses on gesture as one component of the doing of teaching and learning and documents some of the ways that participants use their hands and bodies while displaying what they know. It provides grounds for a view of gesture as the embodiment of thinking. Gestures, by this view, are material signs that embody the knowledge being articulated while simultaneously serving to shape and lend structure to social interaction. Extending our understanding of how this is actually accomplished is foundational to our understanding of cognition and instruction as intersecting forms of interactional achievement. Much work remains to be done, however, to carefully document the practices of sense making in instructional settings. Such work holds the 
key, not only to understanding how learner articulation is accomplished, but also to giving an adequate account of what makes any exemplary form of instruction effective.

\section{Acknowledgements}

We thank Elaine Crowder, Chuck Goodwin, Jeremy Roschelle and one anonymous reviewer for their many helpful suggestions for improving this paper. 


\section{References}

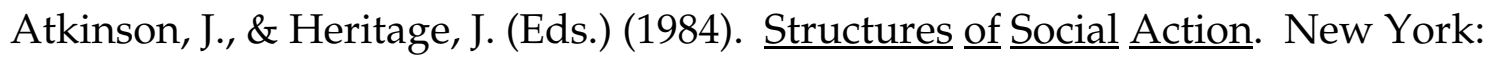
Cambridge University Press.

Barrows, H.S. (1994). Practice-based learning: Problem-based learning applied to medical education. Springfield, IL: Southern Illinois University School of Medicine.

Beach, W., \& LeBaron, C. (in prep). Body disclosures: Attending to personal problems and reported sexual abuse in a medical encounter. Journal of Communication.

Bielaczyc, K., Pirolli, P., \& Brown, A. (1995). Training in self-explanation and selfregulation strategies: Investigating the effects of knowledge acquisition activities on problem solving. Cognition and Instruction, $\underline{13}, 221-252$.

Brown, A.L., Day, J.D., \& Jones, R.S. (1983). The development of plans for summarizing texts. Child Development, $\underline{54}, 968-979$.

Chi, M., Bassok, M., Lewis, M., Reiman, P., \& Glaser, R. (1989). Self-explanations: How students study and use examples in learning to solve problems. Cognitive $\underline{\text { Science, }} \underline{13}$, $145-182$.

Chi, M., de Leeuw, N., Chiu, M-H, \& LaVancher, C. (1994). Eliciting self-explanations

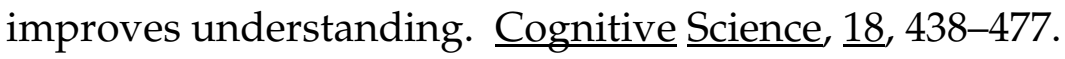

Church, R. B. \& Goldin-Meadows, S. (1986). The mismatch between gesture and speech as an index of transitional knowledge. Cognition, $\underline{23}, 43-71$.

Church, R. B., Schonert-Reichl, K., Goodman, N., Kelly, S.D., \& Ayman-Nolley, S. (1995). The role of gesture and speech communication as a reflection of cognitive understanding. Journal of Contemporary Legal Issues, $\underline{6}, 237-280$.

Coleman, E. (1998). Using explanatory knowledge during collaborative problem solving in science. Journal of the Learning Science, $\underline{7}, 387-427$.

Crook, C. (1994). Computers and the collaborative experience of learning. London: Routledge. 
Crowder, E. (1996). Gestures at work in sense-making science talk. Journal of the Learning Sciences, $\underline{5}, 173-208$.

Crowder, E. \& Newman, D. (1993). Telling what they know: The role of gesture and

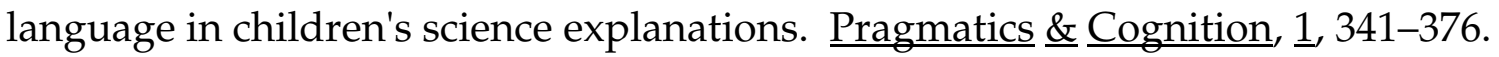
de Fornel, M. (1992). The return gesture: Some remarks on context, inference, and iconic gesture. In P. Auer \& A. di Luzio (Eds.), The contextualization of language (pp. 159-176). Philadelphia: John Benjamins.

Distlehorst, L.H., \& Barrows, H.S. (1982). A new tool for problem-based self-directed learning. Journal of Medical Education, 57, 466-488.

Drew, P., \& Heritage, J. (1992). Analyzing talk at work: An introduction. In P. Drew \& J. Heritage (Eds.), Talk at work (pp. 3-65). Cambridge: UP.

Duranti, A. (1997). Linguistic anthropology. New York: Cambridge University Press.

Forman, E. \& Larreamendy-Joerns (1998). Making explicit the implicit: Classroom explanations and conversational implicatures. Mind, $\underline{\text { Culture }}, \underline{\text { and }} \underline{\text { Activity, }} \underline{5}, 105-$ 113.

Goldin-Meadows, S., Alibali, M., \& Church, R.B. (1993). Transitions in concept acquisition: Using the hand to read the mind. Psychological Review, 100, 279-297.

Goldin-Meadows, S., Wein, D., \& Chang, C. (1992). Assessing knowledge through

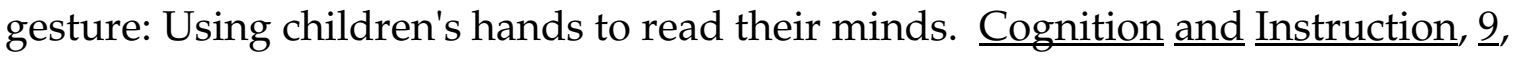
201-219.

Goodwin, C. (1981). Conversational organization: Interaction between speakers and hearers. NY: Academic Press.

Goodwin, C. (1986). Gestures as a resource for the organization of mutual orientation. Semiotica, $62,29-49$.

Goodwin, C. (in prep). Pointing as situated practice. In Sotaro Kita (Ed.), Pointing: Where language, culture and cognition meet. Mahwah, NJ: Lawrence Erlbaum Associates. 
Goodwin, M.H. \& Goodwin, C. (1986). Gesture and coparticipation in the activity of searching for a word. Semiotica, $\underline{62}, 51-75$.

Hall, R. (1999). The organization and development of discursive practices for "Having a Theory." Discourse Processes, 27, 187-218.

Halliday, M.A.K. \& Hasan, R. (1976). Cohesion in English. London: Longmans.

Hamilton, R. (1989). The effects of learner-generated elaborations on concept learning from prose. Journal of Experimental Education, 57, 205-216.

Hatano, G. \& Inagaki, K. (1991). Sharing cognition through collective comprehension activity. In L.B. Resnick, J. Levine, \& S.D. Teasley, Perspectives on socially shared cognition (pp. 331-348). Washington, DC: APA.

Heath, C. (1986). Body movement and speech in medical interaction. New York:

Cambridge University Press.

Heath, C. (1988). Embarrassment and interactional organization. In P. Drew \& A. Wootton (Eds.), Erving Goffman: Exploring the interaction order (pp.136-160). Boston: Northeastern University Press.

Hindmarsh, J. \& Heath, C. (2000). Embodied reference: A study of deixis in workplace interaction. Journal of Pragmatics, 32, 1855-1878.

Hutchins, E. \& Palen, L. (1997). Constructing meaning from space, gesture, and speech.

In L. B. Resnick, R. Säljö, C. Pontecorvo, \& B. Burge (Eds.), Discourse, tools, $\underline{\text { and }}$ reasoning: Essays on situated cognition (pp. 24-40). Berlin: Springer-Verlag.

Jordan, B. \& Henderson, A. (1995). Interaction analysis: Foundations and practice. Journal of the Learning Sciences, $\underline{4}, 39-104$.

Kendon, A. (1987). On gesture: Its complementary relationship with speech. In A.W.

Siegman \& S. Feldstein (Eds.), Nonverbal Behavior and Communication (pp. 65-97).

Hillsdale, NJ: Lawrence Erlbaum Associates.

Kendon, A. (1990). Conducting interaction: Patterns of behavior in focused encounters. New York: Cambridge University Press. 
Koschmann, T. (Ed.) (1999). Special issue on meaning making. Discourse Processes, $\underline{27}(2)$.

Koschmann, T., Glenn, P., \& Conlee, M. (2000). When is a problem-based tutorial not tutorial? Analyzing the tutor's role in the emergence of a learning issue. In D.

Evensen \& C. Hmelo (Eds.), Problem-based learning: $\underline{\text { A research perspective on }}$ learning interactions (pp. 53-74). Mahwah, NJ: Lawrence Erlbaum Assoc.

Koschmann, T., Kelson, A., Feltovich, P., \& Barrows, H. (1996). Computer-supported PBL: A principled approach. In T. Koschmann (Ed.), CSCL: Theory and practice of an emerging paradigm (pp. 83-124). Mahwah, NJ: Lawrence Erlbaum.

Krauss, R.M., Morrel-Samuels, P., \& Colasante, C. (1991). Do conversational gestures

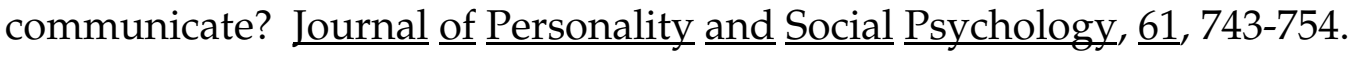

LeBaron, C. (1998). Building communication: Architectural gestures and the embodiment of new ideas. Dissertation Abstracts International, 59-06, 1835. [University Microfilms No. AAT9838026]

LeBaron, C., \& Streeck, J. (2000). Gesture, knowledge, and the world. In McNeill, D. (Ed.), Language and gesture. Cambridge: University Press.

Lemke, J. (1999). Typological and topological meaning in diagnostic discourse.

Discourse Processes, 27, 173-186.

McNeill, D. (1992). Hands and mind. Chicago: U. of Chicago Press.

McNeill, D. \& Levy, E. (1993). Cohesion and gesture. Discourse Processes, 16, 363-386.

Mead, G.H. (1910). Social consciousness and the consciousness of meaning. Pscyhological Bulletin, $\underline{7}$, 397-405.

Miyake, N. (1986). Constructive interaction and the iterative process of understanding. Cognitive Science, $\underline{10}, 151-177$.

Moerman, M. (1990). Studying gesture in social context. In M. Moerman \& N. Masaichi (Eds.), Culture embodied (Senri Ethnological Studies, No. 27, pp. 5-52). Osaka, Japan: Natural Museum of Ethnology. 
Ochs, E. (1979). Planned and unplanned discourse. In T. Givón (Ed.), Syntax and semantics (Vol. 12): Discourse and syntax, (pp. 51-80). NY: Academic Press.

Ploetzner, R., Dillenbourg, P., Preier, M., \& Traum, D. (1999). Learning by explaining to oneself and to others. In P. Dillenbourg (Ed.), Collaborative learning: Cognitive and computational approaches (pp. 103-121). Oxford, U.K.: Pergamon.

Pressley, M., Wood, E., Woloshyn, V., Martion, V., King, A., \& Menke, D. (1992). Encouraging mindful use of prior knowledge: Attempting to construct explanatory answers facilitates learning. Educational Psychologist, 27, 91-109.

Renkl, A. (1997). Learning from worked-out examples: A study in individual

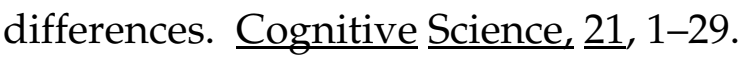

Rimé, B. (1983). Nonverbal communication or nonverbal behavior? Towards a cognitive-motor theory of nonverbal behavior. In W. Doise \& S. Moscovici (Eds.),

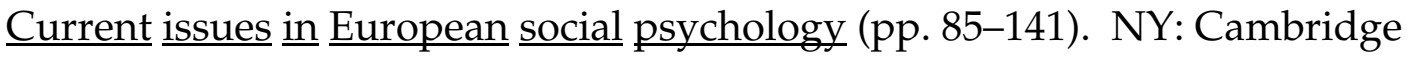
University Press.

Roth, W.-M. (2000). From gesture to scientific language. Journal of Pragmatics, $\underline{32}$, $1683-1714$.

Sacks, H. (1992). Lectures on conversation. Oxford, U.K.: Blackwell.

Sacks, H., \& Schegloff, E. (1979). Two preferences in the organization of reference to persons in conversation and their interaction. In G. Psathas (Ed.), Everyday language:

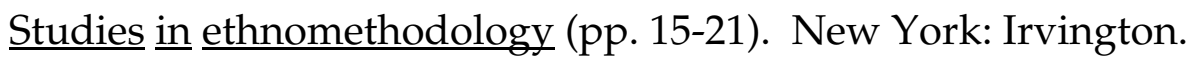

Sacks, H., Schegloff, E., \& Jefferson, G. (1974). A simplest systematics for the organization of turn-taking for conversation. Language, $\underline{50}$, 696-735.

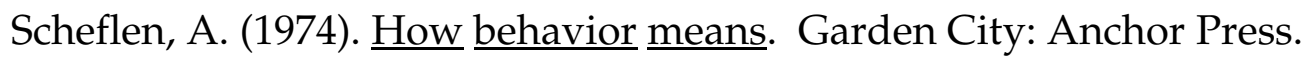

Schegloff, E. (1972). Notes on a conversational practice: Formulating place. In D.

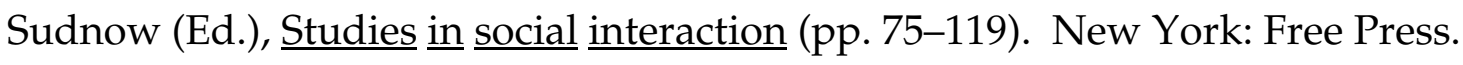


Schegloff, E. (1984). On some gestures' relation to talk. In J.M. Atkinson \& J. Heritage (Eds.), Structures of social action (pp. 266-296). New York: Cambridge University Press

Schegloff, E. (1988). On an actual virtual servo-mechanism for guessing bad news: A single case conjecture. Social Problems, $\underline{35}, 442-457$.

Streeck, J. (1996). How to do things with things. Human Studies, 19, 365-384. van Zee, E.H. \& Minstrell, J. (1997). Reflective discourse: Developing shared understanding in a physics classroom. International Journal of Science Education, 19 , 209-228.

von Raffler-Engel, W. (1986). The transfer of gestures. Semiotica, 62, 129-145.

Webb, N. (19889). Peer interaction and learning in small groups. International Journal of Educational Research, 13, 21-39.

Wittrock, M.C., \& Alesandrini, K. (1990). Generation of summaries and analogies and analytic and holistic abilities. American Educational Research Journal, 27, 489-502. 